\title{
Sterile water injection labour analgesia in a parturient with preeclampsia with thrombocytopenia
}

\author{
Shivali Panwar ${ }^{1 *}$, Divya Arora², Anu Kapur², Kirti Nath Saxena ${ }^{3}$ \\ ${ }^{1}$ Department of Anaesthesiology and Critical Care, North DMC Medical College, Hindu Rao Hospital, New Delhi, \\ India \\ ${ }^{2}$ Department of Anaesthesiology and Critical Care, Hindu Rao Hospital, New Delhi, India \\ ${ }^{3}$ Department of Anaesthesiology and Critical Care, Maulana Azad Medical College and Associated Lok Nayak \\ Hospital, New Delhi, India
}

Received: 22 November 2016

Accepted: 13 December 2016

\section{*Correspondence:}

Dr. Shivali Panwar,

E-mail: shivalipanwar@gmail.com

Copyright: ( ) the author(s), publisher and licensee Medip Academy. This is an open-access article distributed under the terms of the Creative Commons Attribution Non-Commercial License, which permits unrestricted non-commercial use, distribution, and reproduction in any medium, provided the original work is properly cited.

\begin{abstract}
Pregnancy induced hypertension is one of the most common causes of maternal morbidity and mortality. A G2L1A1 female with period of gestation 36 weeks presented in our hospital with early labour pains. She was a known case of pregnancy induced hypertension with thrombocytopenia and had been operated on the lumbar spine for Potts spine. She was administered intradermal sterile water injection labour analgesia every 3 hours. The labour was uneventful and patient had a normal vaginal delivery of a male baby. The postnatal course was uneventful and patient was satisfied with the labour analgesia.
\end{abstract}

Keywords: Labour analgesia, Sterile water injection, Thrombocytopenia

\section{INTRODUCTION}

Pregnancy induced hypertension is defined as hypertension which is seen for the first time after 20 weeks of gestation and which spontaneously disappears after the delivery of the baby. It is associated with an increased incidence of adverse pregnancy outcomes. Thrombocytopenia has been reported to occur in $17-50 \%$ of preeclamptic women., ${ }^{1,2}$

The treatment for preeclampsia including thrombocytopenia is the delivery of the baby which causes rapid resolution of the disease including thrombocytopenia. ${ }^{3}$

We report a case of a parturient with preeclampsia with thrombocytopenia who was administered intradermal sterile water injections for labour analgesia and had a normal uneventful vaginal delivery.

\section{CASE REPORT}

A $\mathrm{G}_{2} \mathrm{~L}_{1} \mathrm{~A}_{1}$ booked 29 year old female with period of gestation 36 weeks presented in the obstetric emergency of our hospital with complaints of pain abdomen. Patient was a known case of pregnancy induced hypertension and was on treatment with oral methyldopa $250 \mathrm{mg} 8$ hourly. On examination the vitals were a heart rate of $96 /$ minute and blood pressure of 170/100 $\mathrm{mm} \mathrm{Hg}$.

The cervix was $2 \mathrm{~cm}$ dilated and the fetal heart rate was $146 /$ minute and patient was put on conservative management in the labour room. A complete hemogram, liver function tests, blood urea, serum creatinine and coagulation profile were sent for analysis. Her laboratory investigations showed a Hemoglobin of $9.3 \mathrm{~g} / \mathrm{dl}$ with a platelet count of $70000 / \mu 1$. The liver, renal function tests and coagulation profile were normal and urine analysis revealed a proteinuria of $1+$. We received a call by the 
obstetrician who requested us to administer labour analgesia to the patient. On evaluation the patient gave us a positive history of Pott's spine 10 years back for which she was operated in another city. However no treatment papers were available with the patient. On examination she had a heart rate of $100 /$ minute and blood pressure of $162 / 104 \mathrm{~mm} \mathrm{Hg}$ and respiratory rate of 22/minute. She had bilateral pitting edema in the feet. The airway, respiratory and cardiovascular system examination was normal. Examination of the spine revealed the presence of surgical scars in the lumbar area. However an x-ray could not be done keeping in mind the safety of the fetus.

In view of the low platelet count and surgical fixation of the lumbar area we planned to avoid central neuraxial anaesthesia (epidural and spinal anaesthesia) and decided to proceed with more conservative method of labour analgesia. An intradermal sterile water block labour analgesia was planned for the patient. The patient was administered four intradermal injections of $0.5 \mathrm{ml}$ sterile water in the lumbosacral region. One injection was administered at the posterior superior iliac spine on both the sides and the other was administered $1 \mathrm{~cm}$ medial and $1 \mathrm{~cm}$ inferior to the posterior superior iliac spine. The injections were repeated at intervals of 3 hours. In the meanwhile the obstetrician arranged platelet concentrates for the patient in anticipation of blood loss during delivery. The patient was transfused 2 unit platelet concentrates by the obstetrician. The labour progressed normally and lasted for 13 hours. She was comfortable during labour and the Visual analog pain scores during labour were as follows (Table 1). She had a normal vaginal delivery of a live preterm male baby weighing 3 $\mathrm{kg}$ who cried immediately after birth and had an Apgar score of 9/10. There was minimal blood loss during delivery. The postnatal course was uneventful and the patient was discharged from the hospital after 7 days. A follow up of the patient done after 4 weeks showed that the patient was satisfied with the labour analgesia.

\section{DISCUSSION}

Pregnancy induced hypertension is one of the most common diseases which are encountered by the obstetricians and anaesthesiologists in daily practise and is one of the major causes of maternal morbidity and mortality and accounts for $10-15 \%$ of maternal death in the developing countries. ${ }^{4}$ In this disorder the platelets have been reported to adhere to the damaged areas of the vascular endothelium which results in the secondary destruction of the platelets. ${ }^{5,6}$

Prostacyclin, an eicosanoid is produced by the vascular endothelium and causes vasodilation and inhibition of platelet aggregation. Deprivation of prostacyclin's seen in pregnancy induced hypertension favours the platelet aggregation and removal of the aggregated platelets from the circulation could be the reason for the thrombocytopenia observed in these patients ${ }^{7}$. It has been reported that thrombocytopenia may be present before the onset of hypertension in these patients, or may even be present without it. ${ }^{8}$

Thrombocytopenia is a concern for the anaesthesiologists as low platelet counts can be associated with a risk of haemorrhage in the spinal canal. A spinal haematoma can cause compression of the spinal cord and neurological deterioration including paraplegia in the patient. There has been a reported case of epidural haematoma in a patient with thrombocytopenia with platelet count of $71 \mathrm{x}$ $10^{9} \mathrm{~g} / \mathrm{dl} .{ }^{9}$ Although the incidence of above complications is rare, but a theoretical risk is present and a cautious approach is warranted.

Technical difficulties may be encountered in performance of central neuraxial blockade in patients who have undergone previous spine surgery. ${ }^{10,11}$ There is loss of tactile sensation of the needle advancement and false loss of resistance due to the existing scar tissue. It may cause difficulty in establishing central neuraxial blockade even to the experienced anaesthesiologists and there may be repeated attempts to secure central neuraxial blockade. This may be detrimental in patients of thrombocytopenia and may increase the risk of spinal or epidural haematoma. An abnormal vertebral anatomy may cause a patchy block and failure of epidural analgesia in these patients.

In view of the above we decided to proceed with intradermal sterile water block labour analgesia in this patient. This technique of labour analgesia involves injecting intradermal sterile water at four different points over the sacrum and is based on the gate control theory of pain. The corpus uteri and cervix are innervated by afferent neurons which end in the dorsal horns of the spinal segments T10-L1. It has been reported that referred pain arising from these nerve roots can be felt over the lower abdomen, pubis, the lower back and sacrum. The intradermal injections cause the firing of delta fibres and the $\mathrm{C}$ fibres. After intradermal sterile water injection the somatic pain input from the A fibres will dominate the visceral pain input from the $\mathrm{C}$ fibres and the patient barely notices the visceral pain. As sterile water is isoosmolar its injection will cause a brief pain which is followed by a long pain free interval. There might also be stimulation of the endogenous opioid system. $^{12-15}$

Our patient was satisfied with the labour analgesia. This case report highlights the importance of intradermal sterile water labour analgesia which can be used as an alternative to the central neuraxial anaesthesia and analgesia in patients of thrombocytopenia. As the technique involves the injections of sterile water it is free from the negative side effects seen with other techniques of labour analgesia.

Funding: No funding sources

Conflict of interest: None declared

Ethical approval: Not required 


\section{REFERENCES}

1. Gibson B, Hunter D, Neame PB, Kelton JG. Thrombocytopenia in preeclampsia and eclampsia. Sem Thromb Haemostas. 1982;8:234-47.

2. Giles C, Inglis TCM. Thrombocytopenia and macro thrombocytosis in gestational hypertension. $\mathrm{Br} \mathrm{J}$ Obstet Gynecol. 1981;88:1115-9.

3. Katz VL, Thorp JM, Rozas L, Bowes WA. The natural history of thrombocytopenia associated with preeclampsia. Am J Obstet Gynecol. 1990;163:114243.

4. Vigil-De Gracia P, Montufar-Rueda C, Ruiz J. Expectant management of severe preeclampsia and preeclampsia superimposed on chronic hypertension between 24 and 34 weeks gestation. Eur J Obstet Gynecol Reprod Biol. 2003;107:24-7.

5. O'Brien WF, Saba HI, Knuppcl RA. Alterations in platelet concentration and aggregation in normal pregnancy and preeclampsia. Am Obstet Gynecol. 1986;1(55):486-90.

6. Burrows RE, Hunter DJS, Andrew M. A retrospective study investigating mechanism of thrombocytopenia in preeclampsia. Obstet Gynecol. 1987:70:334-8.

7. Fitzgerald DJ, Entman SS, Mulloy K. Decreased prostacyclin biosynthesis preceding the clinical manifestation of pregnancy induced hypertension. Circulation. 1987;75:956-63.

8. Redman CWG, Bonnar J, Beilin L. Early platelet consumption in preeclampsia. Br Med J. 1978;i:46770 .
9. Douglas MJ. The use of neuraxial anaesthesia in parturients with thrombocytopenia: what is an adequate platelet count? In: Halpern SH, Douglas MJ eds, Evidence based obstetric anaesthesia. Blackwell Publishing, Massachusetts. 2005: 165-77.

10. Sharrock NE, Urquhart B, Mineo R. Extradural anaesthesia in patients with previous lumbar spine surgery. Br J Anaesth. 1990;65:237-9.

11. Feldstein G, Ramanathan S. Obstetric lumbar epidural anaesthesia in patients with previous posterior spinal fusion for kyphoscoliosis. Anesth Analg. 1985;64:83-5.

12. Melzack R, Wall PD. Pain mechanisms: A new theory. Science. 1965;150:971-9.

13. Hutton EK, Kasperink M, Rutten M, Reitsma A, Wainman B. Sterile water injection for labour pain: a systematic review and meta analysis of randomized controlled trials. BJOG. 2009;116:1158-66.

14. Saxena KN, Nischal H, Batra S. Intracutaneous injections of sterile water over the sacrum for labour analgesia. Indian J Anaesth. 2009;53:169-73.

15. Panwar S, Saxena KN. Sterile water block labor analgesia in a parturient with ventriculoperitoneal shunt in situ. J Obstet Anaesth Crit Care. 2016;6:1921.

Cite this article as: Panwar S, Arora D, Kapur A, Saxena KN. Sterile water injection labour analgesia in a parturient with preeclampsia with thrombocytopenia. Int J Reprod Contracept Obstet Gynecol 2017;6:743-5. 